\title{
Editorial: Canadian Journal on Aging / La Revue canadienne du vieillissement: A Forum for Integration in Geropsychology
}

\author{
Thomas Hadjistavropoulos \\ University of Regina
}

Over 30 years ago, in a comprehensive review of geropsychology published in the prestigious Annual Review of Psychology, Botwinick (1970) identified several core areas within the discipline. These were (1) cognition, (2) perception and psychophysiology, (3) personality and social behaviour, (4) psychological factors that play a role in survival, and (5) analogue studies (e.g., research involving the study of animals) investigating behavioural factors in aging. Additional relevant areas are clinical geropsychology, including clinical geriatric neuropsychology, the broader area of geriatric-health psychology, and others. These areas are representative of the diversity within the discipline of psychology and have seen major developments over the last three decades.

Although Canadian psychologists excel in the core areas of geropsychology, several major areas in which progress has been made are underrepresented among the articles that are submitted and published in the Canadian Journal on Aging/La Revue canadienne de vieillissement. For example, the neuropsychology of aging and dementia, the psychology of pain, and cognitive geropsychology are all under-represented. Fabulous Canadian contributions to the psychology of aging can be found in other venues, in areas as diverse as those involving the experimental study of cognitive processes (e.g., Uttl \& Graf, 1997), animal models relating to the psychology of aging (e.g., Gagliese \& Melzack, 2000), clinical neuropsychology (e.g., Tuokko \& Woodward, 1996), the psychology of pain (Gagliese \& Melzack, 1997), and many others. There are appears to be a perception that the journal does not have the mandate to emphasize or focus on these areas. On the contrary, the journal does have the mandate and can become stronger by showcasing excellent work on these subjects. This will not only have educational value for the readership but will also expand our readership base.

Within my own area, pain psychology, it strikes me that most of our Canadian research colleagues who study pain and aging tend to submit their work to pain journals rather than general gerontology journals. They also tend to attend specialized pain confer- ences more often than they attend gerontology conferences. The net result is that excellent progress made in pain psychology is not effectively disseminated to the general gerontology community. Since most scholars and health care professionals working with seniors are not pain specialists, a generalist journal such as the Canadian Journal on Aging / La Revue canadienne de vieillissement provides wider dissemination.

Bandura (2001) raised concerns about reductionism and fragmentation in psychology and stressed that psychology is an integrative discipline that uniquely encompasses the interplay between intrapersonal, biological, interpersonal, and sociocultural determinants of human functioning. All these areas ought to be represented among the psychology papers published in the journal. Duffy (2003) outlined some of the benefits of organizing psychology around a common interest. In our case, the common interest is aging. The journal is a forum for achieving much needed integration.

I assure the readership that, in my role as Psychology Section Editor, I especially encourage the submission of papers from under-represented areas within geropsychology, both because I believe that the journal provides more effective general dissemination than specialized journals and because I would like all geropsychologists to embrace the journal as a possible outlet for their very best work. The journal is quite well indexed. Most importantly, it is indexed in PSYCHINFO, probably the most prominent database for finding psychological research reports. I also note that, in an effort to speed up the review process, we now encourage electronic submission of manuscripts.

Submitting papers (representing a wide variety of specialties) to the Canadian Journal on Aging / La revue canadienne $d u$ vieillissement has added advantages. Specifically, this journal could help enhance the noble goal of our field to work toward a psychology without boundaries (Latham, 2003). Given the multitude of subspecialties within geropsychology and the proliferation of numerous subspecialty journals focusing on 
pain, neuropsychology, cognitive psychology and other sub-domains, it is difficult for many of us to know what our geropsychology colleagues working outside our subdiscipline are doing. This results, for example, in cognitive geropsychologists often not being aware of work in other areas within the psychology of aging. Suedfeld (2003) pointed out that, as scientists, we are often ignorant of what colleagues from "distinct" subdisciplines might be finding. Consistent with the aforementioned concerns, Birren (1989) observed that the field of geropsychology is data rich and theory poor and that the accumulated knowledge tends to be organized around "microtheories" rather than broader integrative frameworks. Publishing in a journal such as the Canadian Journal on Aging/La revue canadienne $d u$ vieillissement that has a broad readership can help diverse scientific and clinical audiences stay in touch with each other.

The argument can be extended to gerontology in general. A psychology without boundaries (Latham, 2003) also motivates a gerontology without boundaries. There is much to be gained through interdisciplinary collaboration and information sharing. Interdisciplinary information sharing can be done far more effectively through a multidisciplinary aging journal than through one that is discipline specific. Scientists cannot exist in isolation. As Pinker (2002) noted in another context, "None of the scientists is dispensable. An isolated geographer would have to invoke magic to move the continents and an isolated physicist could not have predicted the shape of South America" (p. 70).

\section{References}

Bandura, A. (2001). The changing face of psychology at the dawning of a globalisation era. Canadian Psychology, 42, 12-23.

Birren, J.E. (1989). My perspective on research on aging. In V.L. Bengston \& K.W. Schaie (Eds.), The course of later life: Research and reflections (pp. 135-149). New York: Springer.

Botwinick, J. (1970). Geropsychology. Annual Review of Psychology, 21, 239-272.

Duffy, J. (2003). Boundaryless psychology: A discussion. Canadian Psychology, 44, 249-256.

Gagliese, L., \& Melzack, R. (1997). Chronic pain in elderly people. Pain, 70, 3-14.

Gagliese, L, \& Melzack, R. (2000). Age differences in nociception and pain behaviours in the rat. Neuroscience $\mathcal{E}$ Biobehavioral Reviews. 24, 843-854.

Latham, G. (2003). Toward a boundaryless psychology. Canadian Psychology, 44, 216-217.

Pinker, S. (2002). The blank slate: The modern denial of human nature. New York: Viking.

Suedfeld, P. (2003). Psychology without boundaries: Closing the longest undefended boarder in world. Canadian Psychology, 44, 240-243.

Tuokko, H., \& Woodward, T.S. (1996). Development and validation of a demographic correction system for the neuropsychological measures used in the Canadian Study of Health and Aging. Journal of Clinical and Experimental Neuropsychology, 18, 479-616.

Uttl, B., \& Graf, P. (1997). Color-Word Stroop test performance across the adult life span. Journal of Clinical and Experimental Neuropsychology, 19, 405-420. 